\title{
A potência do Portfólio na Formação Docente em Química: um relato narrativo autobiográfico
}

\author{
The Power of the Portfolio in Docent Formation in Chemistry: an \\ autobiographical narrative account
}

Fernanda Monteiro Rigue (fernanda_rigue@ $@$ hotmail.com)
Universidade Federal de Santa Maria

Alice Copetti Dalmaso (alicedalmaso@gmail.com)

Universidade Federal de Santa Maria

\section{Maria Rosângela Silveira Ramos (maria.ramos@iffarroupilha.edu.br) Instituto Federal Farroupilha}

Resumo: O presente trabalho propõe apresentar a construção do Portfólio como instrumento no percurso formativo inicial docente na atualidade. Para tanto, acerca do caráter metodológico do estudo, iniciaremos por uma breve revisão bibliográfica de caráter qualitativo, acerca da temática proposta. Na sequência, apresentaremos um relato narrativo autobiográfico, o qual registra a experiência e vivência do uso do mesmo, durante a formação inicial em Licenciatura em Química, entre os anos de 2011 e 2015. Assim, entende-se que a formação inicial necessita estimular e provocar os licenciandos, no desenvolvimento de um pensar que problematize e reflita sobre as experiências vividas. Dessa maneira, oportunizando aos futuros docentes os elementos necessários para que possam promover liberdade na criação de artefatos culturais, por meio da mobilização de ferramentas e estratégias propostas ao longo da formação.

Palavras-chave: Portfólio; Narrativa Autobiográfica; Formação Docente.

\begin{abstract}
The present work proposes to present the construction of the Portfolio as an instrument in the initial teacher training course today. Therefore, regarding the methodological character of the study, we will start with a brief qualitative bibliographic review about the proposed theme. In the sequence, we will present an autobiographical narrative report, which records the experience and experience of using it, during the initial training in Chemistry Degree, between the years 2011 and 2015. Thus, it is understood that the initial training needs to stimulate provoke the graduates, in the development of a thinking that problematizes and reflects on the lived experiences. In this way, providing future teachers with the necessary elements so that they can promote freedom in the creation of cultural artifacts, through the mobilization of tools and strategies proposed throughout the training.
\end{abstract}

Keywords: Portfolio; Autobiographical narrative; Teacher Education.

\section{INTRODUÇÃO}


A trajetória formativa de professores e professoras é marcada pelas múltiplas e distintas ações e iniciativas oriundas de diferentes perspectivas e possibilidades de pensamento epistêmico e metodológico, de constituição docente no currículo da formação inicial. Trata-se de pontos de vista e vistas de pontos que apresentam repertórios de formação e atuação docente ao estudante em formação superior, nos cursos de Licenciatura.

O encontro dos discentes com essas múltiplas possibilidades faz parte do seu processo formativo, imprescindível para potencializar vias de conhecer e engendrar modos possíveis de como se relacionar com a docência. A chance de estabelecer um instrumento que contribua no olhar atento e permanente para aquilo que vem sendo desenvolvido e construído na formação inicial de futuros docentes é caminho potente e interessante para que os mesmos se percebam no/com o mundo, afetando e sendo afetados por ele. Assim, ao mencionar os termos instrumento e/ou ferramenta, os quais nas mais variadas situações possibilitam potencializar esse movimento, estamos tratando do Portfólio.

Levando isso em conta, o presente trabalho intenta mobilizar a elaboração do Portfólio como estratégia potente para o alargamento de experiências no percurso formativo docente no contemporâneo. Para tanto, acerca do caráter metodológico destes escritos, propomos inicialmente uma breve revisão bibliográfica de caráter qualitativo (ANDRÉ, 2013) acerca do tema de estudo - Portfólio; seguido por um empreendimento narrativo autobiográfico que, em primeira pessoa, dimensiona as marcas do percurso de construção do portfólio enquanto se vivia a formação inicial docente. O que vai ao encontro do que pensam Dorneles e Galiazzi (2012):

[...] compreende-se que as histórias, ao serem narradas, tornam-se dispositivos para se pensar acerca da formação do professor e, nessa direção, possibilita ao autor da história e ao outro que a lê pensar sobre sua ação docente e sua formação, viabilizando que outras histórias possam ser narradas (p. 258).

Nesse sentido, compreendemos a narrativa autobiográfica como um movimento que diz de uma experiência vivida que, quando deslocada para o campo da formação docente, abre a possibilidade de construção de uma autoria professoral que se "trans- 
forma" (LARROSA, 2004). Também, para Firme e Galiazzi (2014, p. 148) "Nos espaços de formação de professores, é importante que se desenvolva a escrita narrativa da prática docente, uma escrita que expresse a autoria e a sala de aula do professor", por isso, enfatizamos nesse estudo a importante abertura desse espaço no âmbito da formação docente.

A autoria em termos de construção de escrita é produzida pela própria configuração de criação de um espaço de possibilidades de escrever sem definições usuais de escrita, sobre 'o que deve', ou 'como' se deve escrever, academicamente. O receio se apresenta frequentemente como sensação entre futuros professores, quando se encontram com a necessidade de escrever, a partir da necessidade de produzir uma escrita 'desvinculada' do que se sente e se pensa, de um processo de autoria, afinal. Para se tornar autor de algo, a prática de escrita precisa instaurar a sensação de poder articular as palavras com o que é vivido, para “[...] tornar-se, desde então, sempre outra coisa" (DALMASO, 2020, p. 59). Isso, para tanto, só pode ser antecedido a partir de um espaço de abertura que se lapida conjuntamente às vozes dos futuros docentes, ecoadas por seus conflitos legítimos de formação, agruras e anseios, alegrias e conquistas.

No entanto, segundo Garcia (1999), a seriedade e importância da narrativa da própria história formativa faz-se necessária não somente como um ato de conhecimento, mas como um novo caminho na construção do conhecimento. Josso (2007, p. 420) aponta que a reflexão sobre os caminhos de formação só é "[...] produtiva na medida em que os participantes investem ativamente em cada etapa de trabalho neles mesmos, bem como nas interações que o grupo oferece". As especificidades de cada um, as trocas, os tensionamentos, bem como as aprendizagens que se dão no grupo, em meio ao envolvimento e ao empreendimento de dedicação de cada um que habita o coletivo, é esteio primordial para que aconteça a produção de um processo formativo situado na partilha e na comunidade, nas contradições e nas problematizações.

Inspiradas no pensamento de Josso (2004) consideramos que o percurso de formação acontece como um continuum, sendo o indivíduo um constante aprendente. Pela via da pesquisa-formação, Josso (2004) aponta a importância de atentar para as histórias e trajetórias de formação, nas heranças, nos tensionamentos, nas rupturas -

\footnotetext{
${ }^{1}$ Conforme Larrosa (2004) se 'trans-forma' pois sai da forma, estabelece outras possibilidades, horizontes.
} 
como importantes fatores que influenciam diretamente na formação docente. Ou seja, nos movimentos que transformam - pela escrita, por exemplo - o que se vive, em experiência, “[...] implicados pela nossa presença" (JOSSO, 2004, p. 73) e, ao mesmo tempo, por uma atenção ao que se vive. Desse modo,

[...] a simples experiência que consiste em pegar uma caneta e escrever franqueia (como se diz: liberar, desenterrar, retomar um penhor ou retornar a uma fala) uma distância que não pertence nem ao mundo, nem ao inconsciente, nem ao olhar, nem à interioridade, uma distância que, em sua nudez, oferece um quadriculado de linhas de tinta e também um emaranhado de ruas, uma cidade começando a nascer já ali há muito tempo (FOUCAULT, 2006, p. 69).

Uma atenção para os passos e descompassos de um percurso formativo, atravessado e marcado pelas múltiplas relações e vivências desenvolvidas no percurso é horizonte que se abre para que o discente esteja continuamente aprendendo.

Levando isso em conta, na sequência do estudo, será apresentada a potência do Portfólio como desencadeador de um processo que nominamos como autoformativo, seguido por um trabalho de narrativa autobiográfica, tendo em vista a construção de um movimento subjetivo-coletivo.

\section{O PORTFÓLIO COMO POTÊNCIA NA FORMAÇÃO INICIAL DE} PROFESSORES

A elaboração do Portfólio no campo da formação de professores possui um enfoque significativo em estudos que o apontam, entre muitos aspectos, como instrumento de avaliação (VILARINHO; LEITE; RIBEIRO; PIMENTEL, 2017; VILLAS BOAS, 2005). Ao atentar para os estudos de Villas Boas (2005), podemos verificar que a autora considera o seguinte:

[...] o uso do portfólio possibilita o desenvolvimento da construção teórica e prática da avaliação: o trabalho do professor-aluno durante o curso é avaliado por meio de um procedimento que ele poderá desenvolver com seus próprios alunos, com o intuito de superação da avaliação classificatória e excludente. Parte das produções do seu portfólio constitui-se de reflexões sobre as possibilidades do seu uso com seus alunos (p. 294).

Ainda que o Portfólio, como instrumento avaliativo, suscite sensações de estranhamento e encantamento entre professores e estudantes, gerando o que Villas 
Boas (2005, p. 296) chama de “[...] medo, repulsa, dúvidas, insegurança, estresse, sofrimento, questionamento, angústia, preocupação, ansiedade, estranhamento, incompreensão, fardo a mais, rejeição, apreensão, aversão", entendemos que isso também abra possibilidades coletivas (entre docentes, discentes e demais servidores) de refletir sobre a avaliação como constitutiva do espaço institucional - escolarizado - que produz as Licenciaturas. A resistência e dificuldades enfrentadas pelos discentes na construção do Portfólio, sob o ponto de vista no estudo de Villas Boas (2005) aponta para algumas das tantas sensações e sentimentos que tomam relevo quando se pensa a avaliação nos espaços educacionais.

Nesse sentido, é que acreditamos que a construção de um Portfólio pode angariar muitas nuances profícuas em termos de processo de avaliativo, não tão somente com estudantes de Licenciaturas em sua formação acadêmico-profissional, mas com colegas das escolas da Educação Básica (espaços futuros que os estudantes ocuparão), bem como com colegas professores das Universidades, conjuntamente aprendendo as aberturas suscitadas por processos que escapam à lógica avaliativa (e narrativa) habitual, predominante nestes espaços.

Os escritos de Charréu e Oliveira (2015) igualmente são evocados para pensar uma perspectiva não tão somente avaliativa, mas, sobretudo autoavaliativa, como possibilidade suscitada pela construção do Portfólio.

Todavia o traço distintivo mais importante do portfólio é o de constituir uma espécie de autoavaliação para o estudante, levando-o, constantemente, a pensar nos materiais que selecionou ou elaborou, tomando consciência do seu próprio processo de construção do conhecimento e da sua utilização perante um contexto dado (CHARRÉU; OLIVEIRA, 2015, p. 419).

É preciso contingenciar, por sua vez, que a abordagem do Portfólio também pode ser vislumbrada para além de seu uso como parte de um processo avaliativo, compondo de modo a perceber os processos e percursos formativos e autoformativos, estabelecendo a chance do discente desenvolver um olhar mais atento e singular para suas experiências nos diferentes componentes curriculares do curso de Licenciatura.

Quando tratamos de autoformação, entendemos que a produção de um artefato como o Portfólio congregue iniciativas - ações, gestos de escrita, de 'feitura', de mobilização do pensamento e do corpo - que implicam “[...] a produção de si próprio, coletiva e subjetiva" (FELTRIN; BATISTA; BECKER, 2017, p. 02). Nesse sentido, 
esse artefato também pode ser potente para pensar processos autoconstitutivos, autotransformadores de estudantes de escolas básicas, por exemplo, angariando contextos multifacetados das situações e sujeitos escolares do nosso território, em suas especificidades, tantas vezes negadas e sublimadas pela estrutura escolarizada da maioria das instituições educativas.

Encontramos essas potências autoformativas do Portfólio quando Charréu e Oliveira (2015) apontam que:

\begin{abstract}
Em certa medida, o portfólio pode ser entendido como uma "lente macro" que procura abranger todo um horizonte de formação elaborado em determinado momento cronológico. Uma espécie de grande-angular, que procura não deixar de fora aspectos importantes, quer pertençam em concreto à profissão docente, quer integrem o complexo ambiente cultural que caracteriza as escolas e as sociedades contemporâneas (p. 414).
\end{abstract}

Logo, vindo ao encontro dos autores pode-se comparar que o Portfólio é considerado como "[...] um amigo de todas as horas" (CHARRÉU; OLIVEIRA, 2015, p. 419). Os autores apresentam o Portfólio como uma “[...] espécie de "base de dados" (...), de modo que seja facilmente manipulável" (CHARRÉU; OLIVEIRA, 2015, p. 419) passível, portanto, de se recorrer a essa base, quando o estudante, futuramente, precisar acessar aquilo que foi produzido no passado. Ao mesmo tempo, deixam claro que o Portfólio abre a possibilidade de que o professor em formação faça as suas escolhas acerca da linguagem que será adotada no percurso de elaboração.

Ou seja, um Portfólio pode assumir uma diversidade impensada de modulações, formas e linguagens utilizadas em sua construção: escrita, desenho, fotografia, mapa conceitual, cartografia, infográfico, história em quadrinhos, colagens, bem como Portfólios visuais, em seus formatos múltiplos e dissonantes, tais como os descritos em pesquisas de Charréu e Oliveira (2015), nos espaços de estágios supervisionados de Artes Visuais. No entanto, esses recursos de construção do Portfólio, podem ser usados em qualquer área e modalidade de ensino, como no caso que apresentamos reflexões/considerações no que tange ao curso de Licenciatura em Química.

Nesse tom, o Portfólio possibilita uma escrita e organização livre, individual, ou ainda, como o estudo de Firme e Galiazzi (2014) aponta, para a construção do Portfólio como uma possibilidade significativa de desenvolvimento de trabalho em grupo. Assim, a: 
[...] escrita no portfólio coletivo possibilita o desenvolvimento do trabalho em grupo, a partilha de ideias e, principalmente, a construção da responsabilidade de cada participante na elaboração desse mesmo portfólio. É uma possibilidade de formação em grupo, que depende do compromisso de cada participante que nele escreve, lê e reescreve, favorecendo, assim, a discussão no grupo das experiências vivenciadas na escola e nos encontros presenciais do PIBID durante o processo de formação inicial e continuada, articulando a universidade e a escola básica (p.146).

Toma relevo que o processo de construção do Portfólio reflexivo e também de formação "[...] tem, na escrita, a possibilidade, para quem registra, de vivenciar, registrar, lembrar e refletir situações relativas à formação" (FIRME; GALIAZZI, 2014, p. 145). O que corrobora uma preocupação com o âmbito do planejamento coletivo, pela via de uma elaboração escrita acerca das experimentações nas aulas de Química.

O Portfólio coletivo potencializa a atenção para episódios vividos em espaços e tempos distintos na escola e na universidade, estreitando assim as pontes de partilha, de reflexão, de tensionamento e de potencialização acerca dos fazeres que estão no entorno da própria prática docente.

Em outra instância, Nascimento, Ramos e Aroeira (2011, p. 05) consideram que o Portfólio “[...] é um instrumento pedagógico e propulsor da formação docente, pois possibilita documentar experiências, pensamentos e ações oriundas da realidade de ensino (...)". Visto nessa perspectiva, “[...] a construção do portfólio promove o desenvolvimento de algumas habilidades de suma importância como a reflexão, a auto avaliação, análise crítica e a criatividade" (NASCIMENTO; RAMOS; AROEIRA, 2011, p. 04), vindo ao encontro de potencializar a permanente ressignificação do que se vive por parte dos discentes em percurso de formação.

Ademais, conforme aponta Cabral (2019, p. 129) “[...] é importante que esse futuro docente vivencie e reflita sobre a linguagem em sua formação, para que, com maior pertencimento e propriedade, possa incentivar tais práticas na Educação Básica”. Afirmativa que corrobora para que a vivência da leitura e da escrita no âmbito da formação inicial docente seja potencializada, com vistas a alargar o repertório de experimentações vivas e ativas na trajetória formativa, podendo contribuir para as ações futuras do então discente de Licenciatura.

A construção de um Portfólio, parece-nos, abre vias de compreender a formação docente aquém e além da concepção de um 'treinamento' ou capacitação para encarar o mercado de trabalho do licenciando, mas um instrumento que, sobretudo, propicia o 
repensar do fazer educativo, visando a construção da complexa trajetória formativa, em seu caráter, sobretudo, autoformativo, na produção de si mesmo. Entretanto, na perspectiva de Isaia (2006, p. 368), a trajetória de formação é estabelecida na “[...] interrelação das dimensões pessoal e profissional, ao longo do qual o professor se reconhece, formando-se e transformando-se em interação com grupos que lhe são significativos".

Tendo em vista essa possibilidade de pensar o Portfólio como horizonte constitutivo dos debates fluentes e úteis do/no processo formativo como “[...] instrumentos metodológicos da prática pedagógica" (CHARRÉU; OLIVEIRA, 2015, p. 424), para além da avaliação, é que a seguir tramamos um empreendimento narrativo autobiográfico acerca do encontro de uma das autoras do manuscrito com a perspectiva de pensar o Portfólio na formação subjetiva da mesma, sua elaboração, organização e materialização.

Desse modo, o Portfólio, trata-se de um fazer escritural que inaugura o movimento narrativo subjetivo na formação inicial em Química. Uma trajetória de escrita narrativa que atenta para o que foi vivido e experimentado no processo pelo qual se vive a docência, demarcando singularidades e forças ao longo de um habitar discentefuturo docente.

\section{NTARRATIVA AUTOBIOGRÁFICA: A CONSTRUÇÃO DE UM PORTFÓLIO SUBJETIVO-COLETIVO}

Talvez não sejamos outra coisa que um modo particular de contarmos o que somos. E para isso, para contarmos o que somos, talvez não tenhamos outra possibilidade que recorrer de novo às ruínas da nossa biblioteca para intentar lá pegar as palavras que nos nomeiam, que nos dizem (LARROSA, 1995, p. 192).

A proposta de elaboração do Portfólio chegou até mim quando ainda era estudante do primeiro semestre do curso de Licenciatura em Química do Instituto Federal Farroupilha - Campus São Vicente do Sul, entre os anos de 2011 e 2015. Tomou relevo quando estava matriculada em uma disciplina de Práticas Pedagógicas e, a professora responsável pela mesma apresentou-nos uma proposta que nortearia nossas ações durante o percurso formativo no ínterim da Licenciatura em Química (nove semestres letivos) - a elaboração do Portfólio. 
De imediato, a proposta de elaboração do Portfólio durante todo o curso de Licenciatura chegou-me como mais uma tarefa do curso que precisaria realizar ao longo dos quatro anos e meio de graduação. Por sua vez, com o passar dos encontros e dos diálogos coletivos acerca das possibilidades de construção e elaboração do mesmo, o processo de construção do Portfólio passou a se tornar um movimento latente e vivo de pensamento acerca da trajetória de formação inicial em Licenciatura. Um movimento de abertura e criação extremamente ativa e potente.

Meu primeiro anseio ao iniciar a construção do Portfólio esteve motivado pela vontade de estudante de registrar as principais marcas do meu percurso de formação inicial. De encontrar na ferramenta não apenas um espaço de tensionamento e reflexão acerca dos passos e descompassos da formação, mas uma ferramenta de registro que comportaria as nuances de uma trajetória, seus paradoxos, suas contradições, conflitos: aprendizagens. Ferramenta desenvolvida para os encontros de formação (avaliação e metodologia) que, na medida em que é elaborada, constitui-se como artefato cultural. Como efeito de uma produção cultural que constrói significados, intensidades, forças (GIROUX, 1995).

Para isso, mobilizei a construção de um material que comportaria a possibilidade de uma escrita à mão livre, que viabilizasse a inclusão de uma série de fotos, artigos e resenhas de interesse desenvolvidas no transcorrer dos semestres, bem como demais elementos que considerasse pertinentes ao longo da formação. A seguir, segue anexo na Figura 1, um registro do Portfólio elaborado durante a formação inicial em Licenciatura em Química. 


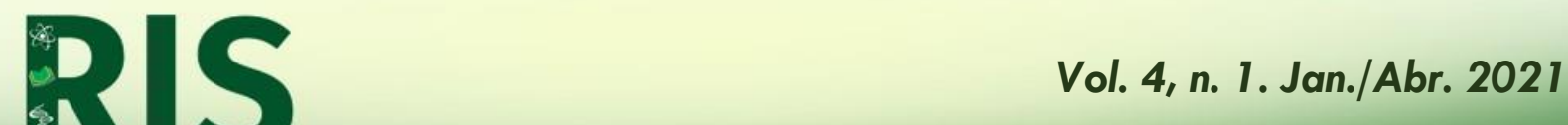

ISSN: 2595- 4520
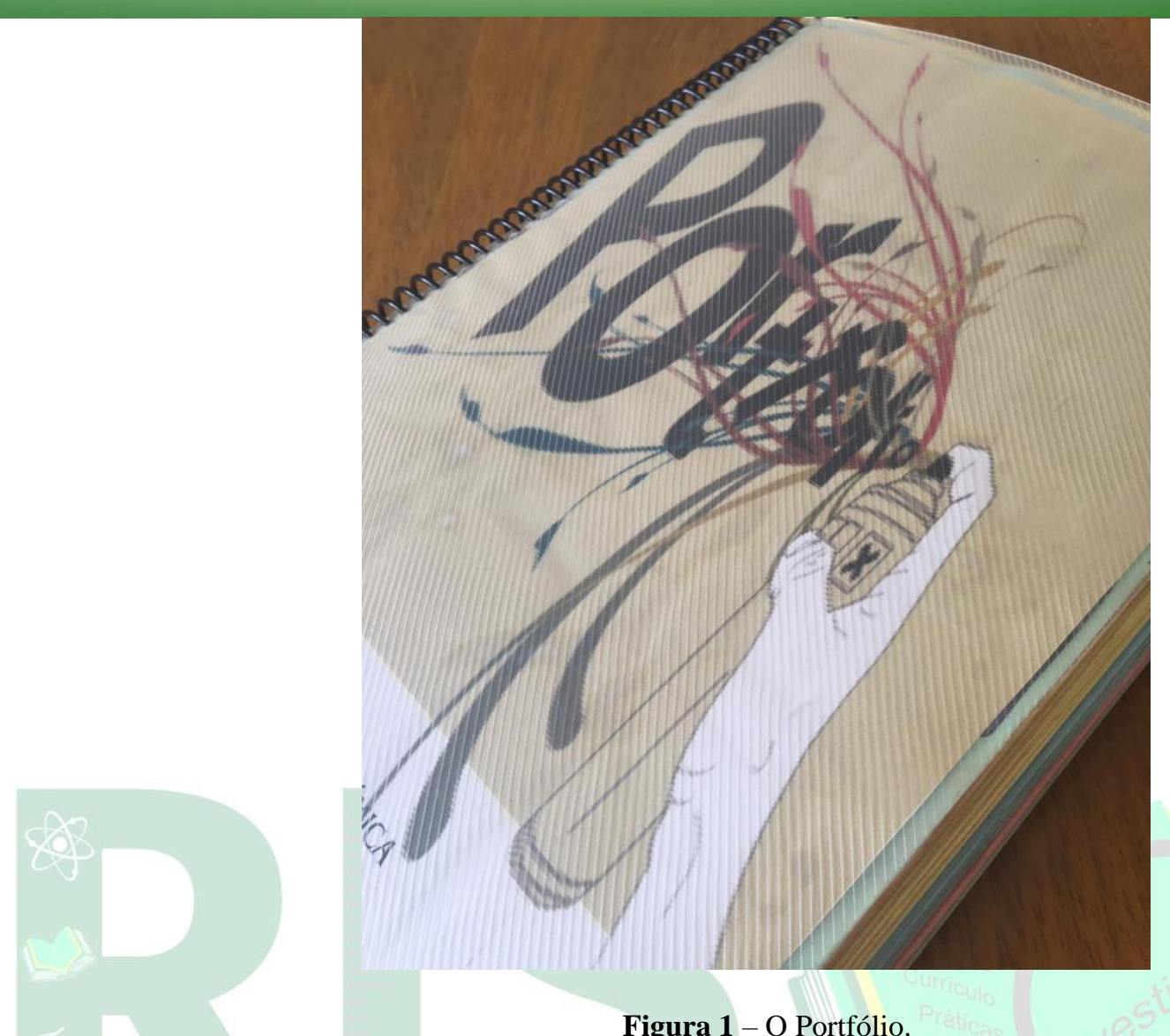

Figura 1 - O Portfólio.

Contendo aproximadamente 100 páginas, o Portfólio - como um processo artesanal - foi organizado tendo em vista a separação por semestres letivos do curso (totalizando nove semestres letivos), conforme apresenta a Figura 2. A cada semestre, desenvolvia um compilado dos principais acontecimentos, que a mim produziam movimentos de reflexão acerca do continuum que se "trans-forma" (LARROSA, 2004) e que acontece em meio ao percurso de formação inicial, demarcando singularidade e, ao mesmo tempo, fatos que estão no âmbito das vivências coletivas.

Em um dos tantos registros que compõe o Portfólio em questão, foi possível assinalar o deslocamento de modificação da ementa do curso de Licenciatura em Química, bem como suas reverberações no corpo discente:

O início do segundo semestre da Licenciatura em Química foi marcado por diversas mudanças na Ementa do curso, as quais causaram impacto de início na maioria dos discentes, mas com o passar do tempo foram sendo entendidas por grande parte da turma. Além disso, foi no iniciar dessa nova jornada que muitos começaram a indagar quais eram seus reais objetivos profissionais dentro do curso, o que levou alguns a desistirem da Licenciatura. Em contrapartida outros, assim como eu renovaram suas forças para continuar construindo seus objetivos, a docência em Química (Portfólio). 
O excerto acima caracteriza o quanto o Portfólio se trata de um empreendimento singular da discente em formação, ao mesmo tempo em que dimensiona os acontecimentos a que está vinculada no curso, produzindo reflexões e apontamentos que a situam no contexto e permitem elaborar compreensões múltiplas e autorais.

Além disso, o processo de elaboração do Portfólio abriu a possibilidade de colocar em fluxo a busca por elementos e processos criativos, que contaram com figuras e registros fotográficos, que traziam para perto o protagonismo da discente, seus gostos, escolhas e modos de apresentação daquilo que pode experimentar durante os semestres e acontecimentos do curso.

Ao passo que me percebia construindo o Portfólio, alargava minha vinculação com o próprio processo formativo. Passava a me sentir cada vez mais vinculada com os caminhos e descaminhos da própria formação. Alargava minhas expectativas acerca dos próximos percursos, realizando uma ampliação do meu leque de atenção para com as leituras e também referências na formação.

Do mesmo modo é preciso pontuar que passados alguns semestres da emergência inicial para a elaboração do Portfólio por parte da professora responsável pela disciplina de Práticas Pedagógicas, foi definida uma data para que nós, estudantes de Licenciatura, realizássemos uma breve apresentação dos nossos percursos singulares de produção do Portfólio. A partir dessa iniciativa foi possível verificar que muitos optaram por não construir seu Portfólio, o que acarretou que apenas alguns realizaram a apresentação de suas produções.

O fato de que alguns discentes não construíram os seus Portfólios pode estar atrelado a uma série de forças que, no âmbito da produção da escrita formal, acabaram restringindo ao longo do tempo a possibilidade de criação escritural - pelo medo de errar, de fazer uma concordância verbal e ortográfica díspar. Uma dificuldade de produzir espaços-tempos de escrita vinculados a vida, as experiências, a autonomia de escrever sobre o que se vivencia no âmbito da formação.

É importante mencionar que, o fato de apenas alguns discentes optarem pela continuidade da elaboração do Portfólio ao longo do curso, não causou nenhuma situação constrangedora ou desconforto. A professora responsável pela disciplina deixou claro que a motivação para continuidade da construção do mesmo ficaria a cargo 


\section{RIS}

Vol. 4, n. 1. Jan./Abr. 2021

ISSN: 2595- 4520

de cada um de nós, sem que isso causasse prejuízo em termos de processo avaliativo na disciplina. Esse modo de condução por parte da professora regente nos aproximou de certa liberdade para a continuidade ou não dos processos singulares de elaboração do Portfólio, vindo ao encontro de fortalecer a noção de que o percurso diria respeito ao nosso querer, como discentes, de fazer acontecer autonomamente esse movimento.

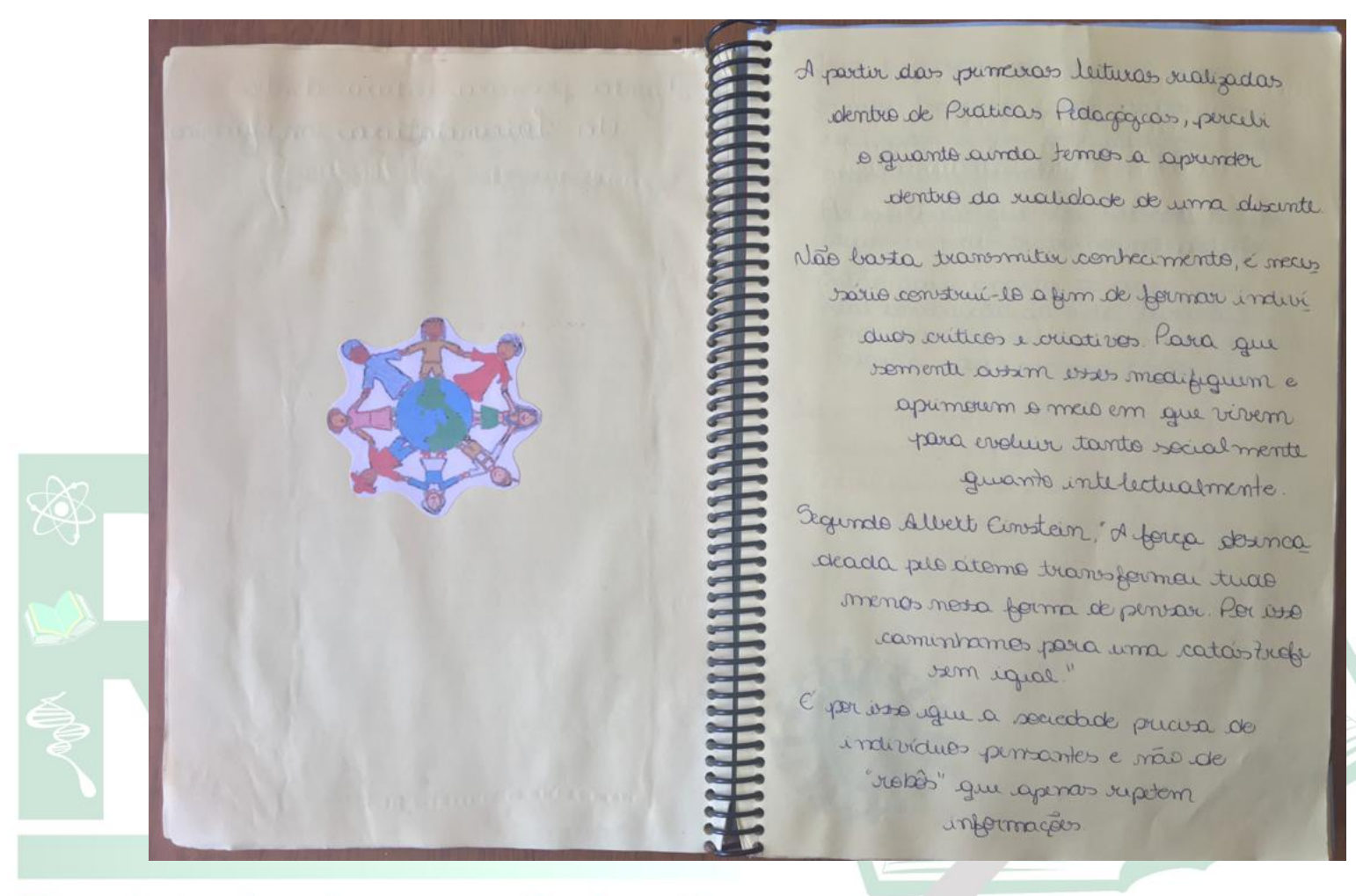

Figura 2-Movimento de escrita do Portfólio.

Levando em conta esse movimento de apresentação dos Portfólios, foi possível visualizar uma série de diferentes escolhas para construção dos mesmos por parte dos discentes. Alguns utilizaram a produção de modo semelhante ao processo o qual eu havia escolhido; outros construíram-no utilizando o processador de texto Microsoft Word; outro colega, ainda, também optou por elaborar o Portfólio no formato de pergaminho.

Sentir-se pertencente e parte do processo formativo é horizonte possível de ser acessado quando o estudante de Licenciatura se percebe produzindo um pensamento e materializando-o com uma série de argumentações, relatos, reflexões e paradoxos vivenciados durante o curso de formação inicial, nesse caso, no curso de Licenciatura em Química. 
Conforme aponta Foucault (2014, p. 231) “O pensamento é liberdade em relação àquilo que se faz, o movimento pelo qual dele nos separamos, constituímo-lo como objeto e pensamo-lo como problema". Nesse tom, a possibilidade de existência discente no curso de formação docente pela via da construção do Portfólio abre o horizonte de habitação ativa e potente nessa experiência - dando a cada um e cada uma a chance de habitar e estar presente de diferentes modos no referido espaço-tempo.

Dessa maneira, a oportunidade da construção do Portfólio na formação inicial, possibilita um 'leque' de variáveis e múltiplas formas de escritas e narrativas. Uma série de práticas de escrita, de invenções de modos de escrever - bem como de agir e de pensar pelas palavras -, podem surgir nesse caminho: digressões, delírios, silêncios, verborragias, ruídos, tornam-se materialidade subjetiva para problematizar o que entendemos por formação. Assim, o "singular do eu" (LARROSA, 1994), juntamente com a liberdade do pensamento (FOUCAULT, 2014), opera com uma estética particular e peculiar de cada ser, abraçando suas nuances, continuidades e descontinuidades de pensamento e escrita - inaugurando, no processo formativo, potencialidades até então impensadas.

A multiplicidade de escolhas linguísticas (CABRAL, 2019) e inventivas é elemento que aponta para a potência da invenção dos discentes na formação inicial quando em contato com uma proposta de construção de Portfólio. O que vem ao encontro de corroborar a significativa capacidade de abertura criativa que a elaboração do Portfólio produz na formação de professores, quando desenvolvida concomitantemente com uma apresentação do mesmo de modo a torná-lo parte da formação - não como tarefa a ser cumprida e executada - ao contrário, como atitude criativa - apropriação do próprio processo formativo.

Elemento indispensável para caracterizar a dimensão formativa de um curso de Licenciatura, já que:

$\mathrm{Na}$ graduação (...) vemos constituir-se, com o passar do tempo, conhecimentos tomados como indispensáveis para que os sujeitos se tornem profissionais de determinado campo. No horizonte das Licenciaturas, por exemplo, esse movimento também acontece, contemplando disciplinas de caráter específico da área, bem como didáticos e metodológicos que dizem respeito à formação pedagógica (RIGUE; FELTRIN, 2020, p. 22). 
Com a mobilização do Portfólio na formação, dá-se coerência a perspectiva de que a “[...] formação (...) está sempre aberta a novas experiências, dúvidas, problematizações" (RIGUE; FELTRIN, 2020, p. 26). Portanto, o Portfólio ocupa um lugar de potencializador da formação pedagógica na formação inicial de professores de Química, viabilizando ao futuro professor um contato com a reflexão sobre as vivências e acontecimentos, tendo a chance de pensar sobre o que experimenta desde o período de formação no Ensino Superior.

Entendemos que a formação de professores segue sendo defendida como um espaço capaz de expandir processos relacionais e comunicativos, necessários para a potencialização de certo tato pedagógico nos futuros professores (DE SOUZA JANERINE; DE QUADROS, 2018). Atestamos, por isso, que a vivência apresentada a partir da produção de um Portfólio na formação inicial de professores de Química, em agenciamento ao campo teórico-conceitual alinhavados em consonância com o vivido, intenta em afirmar novas aberturas ao que podemos, ainda, conceber como processo constitutivo em educação. Entendemos que qualquer espaço educacional, o qual envolva a preocupação com as subjetividades em construção envolvidas, implicam a iniciativa de fabricação de espaços e tempos onde aquilo que está vivo em nós, e em vias de se fazer, possam germinar e crescer. Narração de histórias (DORNELES; GALIAZZI, 2012) e Portfólios irão, então, se avizinhar a uma conjuntura espacial aberta e acessível, mais pensando em seus efeitos coletivos, "Onde as pessoas aprendem diferentes linguagens, se apropriam de recursos para dar conta de si e do seu entorno" (KRENAK, 2020 , p. 34), do que enquanto institucionalização de um novo modo de avaliar, ou meramente instrumentalizar a escolarização.

É desse chão que partimos e que tivemos a intenção de aqui compartilhar. De apresentar a potência do Portfólio na formação inicial, bem como de um relato narrativo autobiográfico que se coletiviza na medida em que está construído em meio a uma subjetividade que se modula em um contexto específico de formação. Uma voz que emerge e toma corpo em um espaço-tempo permeado por ações e empreendimentos de vida em formação, que respingam produzindo afetações e reverberações na formação inicial de professores, nesse caso, os de Química.

\section{CONSIDERAÇÕES FINAIS}


A elaboração do presente estudo teve como objetivo apontar a potência da construção do Portfólio na trajetória formativa de professores. O fizemos considerando as sensações, intensidades, tensionamentos e aprendizagens que emergiam, com base na utilização dessa ferramenta que, na medida em que é mobilizada, constitui-se como artefato cultural potente no processo formativo inicial de professores, nesse caso de Química.

É latente no estudo a pertinência da abertura de possibilidades inventivas no campo da formação de professores, seguida de um alargamento de experiências, gostos e sabores que convoquem os discentes a viverem a liberdade na produção de seus próprios pensamentos, concepções, compreensões e tensionamentos no âmbito da formação inicial.

A formação inicial é uma fase importante para o percurso de construção das concepções e perspectivas daquele que se encontra em processo de aproximação com a docência. É abertura que vem ao encontro de cultivar uma proximidade com a docência com vistas a conjecturar um desenvolvimento de sua autoria na elaboração de materiais didáticos pedagógicos e na construção compartilhada de conhecimentos.

Desse modo, o Portfólio, nesse estudo, aparece como um aliado, como artefato cultural - território possível no processo formativo de professores e professoras em formação, aproximando a chance da construção e consolidação de redes de diálogo entre docentes e discentes; horizonte para que possamos aguçar a atenção aos processos vivenciados na formação inicial; chance para se estar em formação inicial abraçando a possibilidade de construir seu protagonismo.

\section{REFERÊNCIAS}

ANDRÉ, M. E. D. A. de. Estudo de caso em pesquisa e avaliação educacional. Brasília: Liber Livros, 2013.

CABRAL, W. O diário de bordo na formação inicial de professores de Química. Revista Insignare Scientia - RIS, v. 2, n. 2, p. 115-131, 16 set. 2019.

CHARREU, L. V.; OLIVEIRA, M. O. de. Diários de aula e portfólios como instrumentos metodológicos da prática educativa em artes visuais. Cadernos de Pesquisa, São Paulo, v. 45, n. 156, p. 410-425, jun. 2015. 
DALMASO, A. Fiandografia: variações, contaminações, modos (infinitos) de ler e pensar, ler e escrever em educação. In: Fios Invisíveis em Educação. RIGUE, F. M.; OLIARI, G.; STURZA, R. B. (organizadores). 1 ed. Veranópolis: Diálogo Freiriano, p. 53-66, 2020.

DE SOUZA JANERINE, A.; DE QUADROS, A. L. A formação de professores. Revista Insignare Scientia - RIS, v. 1, n. 1, p. 1-21, 18 jun. 2018.

DORNELES, A. M.; GALIAZZI, M. do C. Histórias de Sala de Aula de Professoras de Química: Partilha de Saberes e de Experiências nas Rodas de Formação do PIBID/FURG. Química Nova na Escola, v. 34, n. 4, p. 256- 265, 2012.

FELTRIN, T; BATISTA, N. L; BECKER, E. L. S. A autoformação docente como território de possibilidade: uma reflexão sobre o espaço escolar. RELACult - Revista Latino-Americana de Estudos em Cultura e Sociedade, v. 03, n. 03, set-dez., 2017.

FIRME, M. V. F.; GALIAZZI, M. do C. A Aula Experimental Registrada em Portfólios Coletivos: A Formação Potencializada pela Integração entre Licenciandos e Professores da Escola Básica. Química Nova na Escola, v. 36, n. 2, p. 144-149, 2014.

FOUCAULT, M. Distância, Aspecto, Origem. In: Ditos \& Escritos, Volume III: estética: literatura e pintura, música e cinema. Organização e seleção de textos de Manoel Barros da Motta. Rio de Janeiro: Forense Universitária, p. 60-74, 2006.

FOUCAULT, M. Em busca do presente perdido. In: Ditos \& Escritos, Volume X: filosofia, diagnóstico do presente e verdade. Organização, seleção de textos e revisão técnica de Manoel Barros da Motta. Rio de Janeiro: Forense Universitária, p. 17-18, 2014.

GARCIA, C. M. Formação de professores: para uma mudança educativa. Portugal: Porto Editora, 1999.

GIROUX, H. A. Memoria e pedagogia no maravilhoso mundo da Disney. In: SILVA, T. T. da. Alienígenas na sala de aula: uma introdução aos estudos culturais em educação. Petrópolis: Editora Vozes, p. 132-158, 2005. 
ISAIA, S. Processo Formativo Docente. In: MOROSINI, M. C. (Org.). Enciclopédia de pedagogia universitária, v.2, p. 351, 2006.

JOSSO, M.-C. Experiências de vida e formação. São Paulo: Cortez, 2004.

JOSSO, M.-C. A transformação de si a partir da narração de histórias de vida. Educação, Porto Alegre/RS, n. 3 (63), p. 413-438, set./dez, 2007.

KRENAK, A. A vida não é útil. São Paulo: Companhia das Letras, 2020.

LARROSA, J. Tecnologias do eu e educação. In: SILVA, T. T. O sujeito da educação. Petrópolis: Vozes, p. 35-86, 1994.

LARROSA, J. Las paradojas de la autoconciencia. In: LARROSA, J. et al. Déjame que te cuente - ensayos sobre narrativa y educación. Ed. Laerte. Barcelona, 1995.

LARROSA, J. Linguagem e educação depois de Babel. Belo Horizonte (MG): Editora Autêntica, 2004.

NASCIMENTO, J. V.; RAMOS, T. T.; AROEIRA, K. P. A formação do professor: contribuição do processo de estágio supervisionado em educação física. Fiep Bulletin, v. 81, edição especial, artigo 1, 2011.

RIGUE, F. M.; FELTRIN, T. Educação Escolar e Formação de professores no Brasil: um ensaio possível. In: RIGUE, F. M.; FELTRIN, T.; BATISTA, N. L. Educação no Brasil: perspectivas, horizontes e possibilidades (v. 1). Rio de Janeiro: Dictio Brasil, p. 15-37, 2020.

VILARINHO, L. R. G.; LEITE, L. S.; RIBEIRO, M. B.; PIMENTEL, S. R. G. O Portfólio como Instrumento de Avaliação: uma análise de artigos inseridos na base de dados e-AVAL. Meta: Avaliação. Rio de Janeiro, v. 9, n. 26, p. 321-336, maio/ago, 2017.

VILLAS BOAS, B. M. de F. O Portfólio no curso de Pedagogia: ampliando o diálogo entre professor e aluno. Educação e Sociedade, Campinas, vol. 26, n. 90, p. 291-306, jan./abr, 2005. 